\title{
Influences of Indigenous Community on Sal Forest of Bangladesh
}

\author{
Md Tanbheer Rana \\ Forestry and Wood Technology Discipline, Khulna University-9208, Bangladesh \\ Faculty of Forest Sciences and Forest Ecology, Georg-August-Universität Göttingen, Germany
}

Background: Bangladesh is a populated country with a total population of 161.083 million people living in a density of 1237.51 per square kilometre (CIA World Fact Book 2012) and natural forest coverage is 835,000 hectares (excluding parks and sanctuaries), which accounts for just 5.8 percent of the total land area. Due to lower economic condition, approximately 40 percent people live below poverty line and its found that a positive correlation in between deforestation and poverty.

Deforestation occurs due to the use of fuel wood, fodder and other forest products by local poor people (WCED, 1987; Timberlake, 1985; Anderson and Fishwick, 1984; IUCN, 1980)

Key Words: Bangladesh, Sal Forest, Indigenous Community, Influences on Sal Forests, Critical Situations, Discussion

\section{Short Illustration}

The project was mainly formulated in Altadighi National Park which is situated in Paikbandha range at DhamoirhatUpazilla in Naogaon under the Rajshahi social forestry division under Dhamoirhat bitwhere different indigenous communities live. They live close to Sal forest and are always in touch of the Forest Department, NGOs and other organisations.

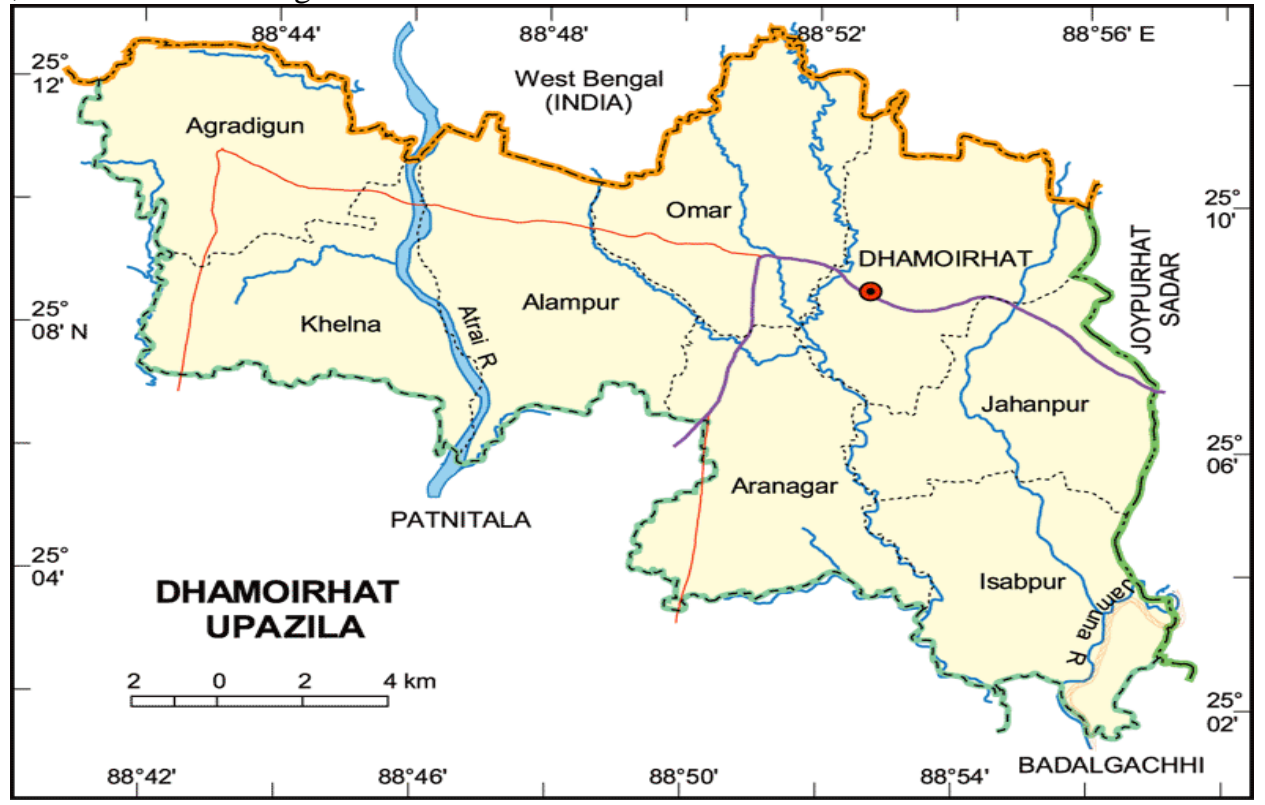

Fig 1: Projected Area ( Dhamoirhat)

\section{Project Formulation}

The total area covered by this national park is about 264.12 ha with 131.57 ha protected forest, 35.49 ha reserved forest and 97.06 ha acquired forest. In which 429 acre area is dominated by Sal forest. There is composition of different species along with the Sal (Shorearobusta), Bael (Aeglemarmelos), Jam (Syzygiumcumini), Chatim (Alstoniascholaris), Haritaki (Terminaliachebula), Neem (Azadirachtaindica), Bahera (TerminalliBelerica)etc with different birds, snakes, frogs and few other wild animals.

Forest Department of Bangladesh is working there to increase the diversity of species and maintain sustainable condition in Sal forest area but due to some misdistribution of benefit sharing, conflict with local people took place. So, NGO's like Padakhep started their work for social forestry programme associated with Forest Department to promote forest development taking concern of local people.

According to Social Forestry Rules in 2004 and modified rule in 2010 gives concept to elaborate the rights and responsibilities of participants (indigenous people who are working to maintain sustainable growth 
of Sal forest), organizations and committees with regard to a range of activities, from site selection to harvesting.

\begin{tabular}{|l|c|}
\hline Shareholders & Percentage \\
\hline Participants & 55 \\
\hline Land Owner & 20 \\
\hline Forest Department & 10 \\
\hline Tree Farming Fund & 10 \\
\hline Local Union Authority & 5 \\
\hline Total & 100 \\
\hline
\end{tabular}

\section{Influences of Indigenous People on Sal Forest}

Tribal community named Santals associated with few Bengali communities are living close to the Sal forest. They are more or less dependent on the forest for their livelihood.

- Local people collect fuel wood and dried leaves from forest which sometimes disturbs the regeneration of forest and cause nutrient deficiency in soil if the extraction is so high. Because we know that debris and leaves play a significant role in forest nutrient dynamics,

- Tribal community are dependent mostly on hunting of wild animals that made Sal forest severely losing diversity of wild animals,

- Indigenous community people are gathering food, fruits, medicinal plants from the forest which cause extinction of some precious medicinal plants,

- Sometimes, seedlings are collected to make roof together with other thatching materials from forest that adversely affects the regeneration.

- Due to some conflict among Forest Department and Santals, Santals are illegally felling trees and collecting non wood forest products.

- Illiterate local people are hardly aware of consequences of forest loss since long time that makes them use forest product unconsciously and leaving the idea of sustainable management of Sal forest.

- Forest firing also changes the structure of forest which is mainly done by ethnic people for some traditions.

$\bullet$

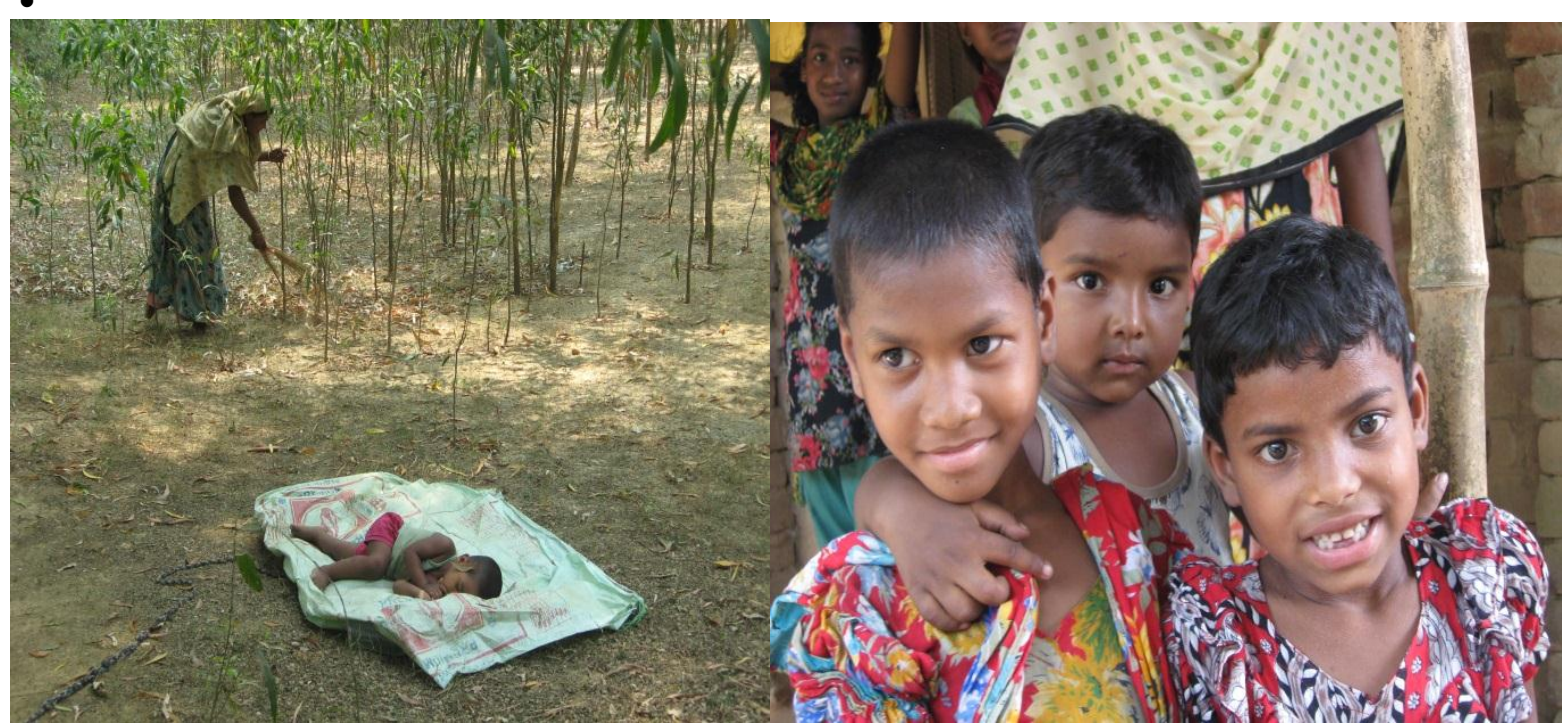

Fig 2: Collection of Dead LeavesFig 3: Tribal Children

\section{Possible Solutions with discussion}

- Perfect implementation of benefit sharing of social forestry programme is to be ensured to satisfy local people with other shareholders.

- Infrastructure improvement (Schools, Roads, Houses, Clinics etc.) should be promoted in order to provide knowledge, training, awareness etc.

- Cultural and recreational facilities must be taken into account to reduce the adverse impact on Sal forest, for example; Playgrounds, Temples etc.

- Sense of self-reliance should be built upproperly as people cancare forest in perfect manner and find alternative income sources other than forest. 
- Leader from the society is to be formulated to represent the society and forest to Forest Departments and NGO's.

- Forest Department and NGO's should provide sufficient alternative sources of fuel wood, fodder, medicine, food and other basic requirements.

- Incentives and other financial supports to the local poor people can enhance the programme through a sustainable way.

\section{Critical Situations}

- "Plant tree, you will get money" this statement of Forest Department was not believed because of inappropriate implementation. So, it took a long time to motivate the people by the help of NGO's.

- In many cases the destitute local people were deprived from the benefits of the different programmes, only the powerful peoples were getting facilities. Due to the influence of these powerful peoples, complains of the poor people were overlooked. But situation is improving now-a-days gradually.

- The collection of fuel wood (leaves, branches) and other means (potatoes, rats, crabs, wild cats) became restricted by declaring the Sal forest as Protected Forest, people needs alternative resources those are recently provided by different NGO's, for example; Providing loan, Domestic animals, Share of total income of different social forestry programmes etc.

\section{References}

[1]. WCED, 1987; Timberlake, 1985; Anderson and Fishwick, 1984; IUCN, 1980

[2]. FAO forestry paper 172, Climate change guidelines for forest managers

[3]. Restoration and Conservation of Biodiversity in BarindDhamoirhat Sal Forest Project, Naogaon

[4]. FAO. 2010c. Global Forest Resources Assessment 2010 - key findings. Rome. foris.fao.org/static/data/fra2010/keyfindings-en

[5]. Action Plan for Implementing the Convention on Biological Diversity's

[6]. IUCN Bangladesh. 2000. Red Book of Threatened Amphibians and Reptiles of Bangladesh. IUCN-The World Conservation Union. xii $+95 \mathrm{pp}$.

[7]. Ervin, J. 2003. WWF: Rapid Assessment and Prioritization of Protected Area Management (RAPPAM) Methodology. WWF International, Gland, Switzerland. 52p.

[8]. IUCN, 2002 . Bio-ecological Zones of Bangladesh. IUCN- The World conservation Union.

[9]. CIA World Fact Book 2012. 